\title{
A INFLUÊNCIA DA GESTÃO DO CONHECIMENTO E DA GESTÃO DA QUALIDADE EM UMA EMPRESA DO RAMO ALIMENTÍCIO DA CIDADE DE SANTA MARIA - RS
}

\author{
Thalles Vargas de Vargas ${ }^{1}$, Mateus de Brito Nagel2 ${ }^{2}$, \\ Andrielle Moraes Dias ${ }^{3}$, Leandro Dorneles dos Santos ${ }^{4}$
}

RESUMO: 0 presente estudo foi realizado para integrar os saberes da gestão do conhecimento e da gestão da qualidade, por meio de um estudo de caso em uma empresa do ramo alimentício da cidade de Santa Maria. A pesquisa teve caráter exploratório e descritivo, de cunho quali-quantitativo, com objetivo de analisar as influências das duas áreas no desenvolvimento de uma organização. Assim, encontrou-se como resultado que a gestão do conhecimento é utilizada de forma ampla na disseminação do conhecimento interno e externo a todos os colaboradores, visto que, a uma conscientização de todos da equipe sobre os objetivos a serem alcançados e que as ferramentas da gestão da qualidade ainda podem ser mais exploradas.

Palavras-chave: Gestão do Conhecimento. Gestão da Qualidade. Interdisciplinaridade.

Submissão: $13 / 05 / 2019$

Aceite: $23 / 05 / 2019$

DOI: $10.47591 / 2674-9203.2019 v 1 n 1 . a r t 5-45-54$

\section{(c) (1) (9)}

Este trabalho está licenciado com uma Licença Creative Commons Atribuição-NãoComercial 4.0 Internacional.

\footnotetext{
${ }^{1}$ E-mail: vthalles66@gmail.com

${ }^{2}$ E-mail: mateus.nagel@fisma.com.br

${ }^{3}$ E-mail: andrimoraesdias@gmail.com

${ }^{4}$ E-mail: leandro.dorneles@ fisma.com.br
} 


\section{INTRODUÇÃO}

A busca por uma formação dinâmica e completa, introduziram novos métodos de aprendizagem dentro das instituições de ensino superior, com o uso de práticas que levem os alunos, a relacionar o conteúdo apresentado dentro da sala de aula, com o ambiente externo. A partir dessa visão, a interdisciplinaridade é introduzida para colaborar na formação in loco, onde é colocado em prática o conteúdo aprendido em sala de aula (DELLA MEA, 2018).

Nesse contexto, será possível buscar informações necessárias para a detenção do conhecimento dentro da organização. Deste modo, a gestão do conhecimento caracteriza-se pela capacidade de gerenciar, descobrir, mapear, captar e reter o conhecimento com eficiência, para que a organização se mantenha de forma competitiva em relação às outras empresas, gerando maior lucro (DRUCKER, 2000).

Contudo, a empresa na detenção de um plano de negócios sólido, com informações claras, obtém assim o conhecimento necessário para dar continuidade nos processos, fazendo-se necessário a gestão da qualidade para definir processos, ações e uma estrutura específica para o alcance da qualidade (SEBRAE, 2016).

Por meio do conteúdo exposto, o presente estudo foi realizado na empresa "Cheirinho de Doce", a qual atua no ramo alimentício, comercializando produtos caseiros, com preparos artesanais sem adição de conservantes. A empresa iniciou suas atividades informalmente, atendendo pedidos de amigos que foram divulgando seus produtos a outras pessoas, dessa forma, percebeu-se um potencial para a expansão do negócio, tornando-se sua principal fonte de renda dos proprietários da empresa.

Nesse contexto, questiona-se a relação entre as disciplinas de Gestão do Conhecimento e Gestão da Qualidade, na execução do plano de negócios desenvolvido para a criação da empresa, norteando as atividades a serem desenvolvidas. Assim, tem-se como problema de pesquisa do presente estudo: Qual a relação da gestão do conhecimento e da gestão da qualidade na estrutura por meio de um diagnóstico, em uma empresa do ramo alimentício da cidade de Santa Maria/RS?

A fim de resolver esta questão, foi definido como objetivo geral da pesquisa, realizar um diagnóstico envolvendo a gestão do conhecimento e a gestão da qualidade em uma empresa localizada em Santa Maria. Para facilitar o alcance do objetivo geral, este foi desmembrado em objetivos específicos, sendo eles: verificar quais ferramentas da qualidade, indicadores de qualidade e, certificações relacionadas a qualidade e produtividade, existem e/ou são necessárias a empresa; avaliar as dimensões da estruturação da gestão do conhecimento na empresa; descrever a relação entre as áreas para a gestão empresarial; e propor sugestões de melhoria para cada área estudada.

Assim, o desenvolvimento da pesquisa se justificou com base no aprendizado proporcionado a comunidade acadêmica, podendo verificar elementos dos conteúdos desenvolvidos em aula, na realidade de uma empresa. A empresa como detentora da realidade ganha assim um estudo amplo de sua estrutura que por muitas vezes por tratar-se do cotidiano não percebe muitos fatos. 


\section{REFERENCIAL TEÓRICO}

Neste capítulo serão abordados os fundamentos teóricos que embasam o estudo realizado. Serão abordadas a gestão do conhecimento e a gestão da qualidade.

\subsection{GESTÃO DO CONHECIMENTO}

Por meio do esclarecimento da importância de um plano de negócios para a abertura de uma nova empresa, independente do porte da mesma, é possível descrever a relação do plano com a gestão do conhecimento organizacional. Assim, a criação uma posição competitiva no mercado só é possível com o auxílio de conceitos como aprendizagem, conhecimento e competência (SHINYASHIKI et al., 2003).

O desenvolvimento desses conceitos, dentro da organização podem ser facilitadores no caminho do sucesso da mesma, assim, tornando-se recursos intangíveis oferecendo uma maior vantagem competitiva. Esse conhecimento só é desenvolvido com a criação e desenvolvimento nos processos de aprendizagem dentro da organização (SHINYASHIKI et al., 2003).

A gestão do conhecimento é uma área dentro da organização que contribui para a compreensão de como os recursos intangíveis podem formar uma base estratégica competitiva, assegurando que a empresa atinja resultados superiores no futuro na identificação dos ativos estratégicos. Nesse sentido, o redimensionamento do conhecimento dentro da organização tem se dado a partir da realidade da mesma, que possui um grande volume de conhecimento interno, ao qual é pouco trabalhado (SHINYASHIKI et al., 2003).

Portanto, com o desenvolvimento dos conceitos embasados dentro da gestão do conhecimento, é possível se relacionar com o mercado externo de forma mais eficiente e competitiva. Para a manutenção dessas estratégias, desenvolvemse as questões relacionadas aos papéis que cada colaborador deve assumir frente à organização, por meio de uma gestão pela qualidade dentro dos produtos e serviços oferecidos a sociedade, que a organização está inserida.

O diagnóstico para a estruturação da gestão do conhecimento envolve duas linhas paralelas: tático e estratégico, os quais em conjunto envolvem sete seções. Tático é a utilização do conhecimento no dia a dia para responder as demandas ou às oportunidades do mercado, fazem parte do processo tático às seguintes seções: obtenha, utilize, aprende e contribua (BUKOWITZ; WILLIAMS, 2002).

Já o estratégico (de mais longo prazo), refere-se à combinação intelectual com as exigências estratégicas, fazendo parte desse processo às seguintes seções: avalie, construa/mantenha e descarte (BUKOWITZ: WILLIAMS, 2002).

Os desafios que caracterizam os processos estão melhores explicadas abaixo:

Quadro 1 - As 4 dimensões da Gestão do Conhecimento

\begin{tabular}{|c|l|}
\hline \multicolumn{1}{|c|}{ SESSÃO } & \multicolumn{1}{c|}{ FUNDAMENTO } \\
\hline Obtenha & $\begin{array}{l}\text { Buscar as informações necessárias para tomar as decisões, resolver problemas } \\
\text { e inovar. Tendo como dificuldades um grande volume de informações. }\end{array}$ \\
\hline
\end{tabular}


Thalles Vargas de Vargas, Mateus de Brito Nagel, Andrielle Moraes Dias, Leandro Dorneles dos Santos

\begin{tabular}{|l|l|}
\hline Utilize & $\begin{array}{l}\text { Ocorre a combinação de informações de formas ovas e interessantes, assim } \\
\text { promovendo a inovação organizacional. }\end{array}$ \\
\hline Aprenda & $\begin{array}{l}\text { Refere-se ao processo formal de aprendizagem, a partir de experiências como } \\
\text { meio para criar vantagens competitivas. }\end{array}$ \\
\hline Contribua & $\begin{array}{l}\text { Ação dos colaboradores de registrar o aprendizado como base do conhecimento } \\
\text { coletivo. Prática tomada, para minimizar os erros cometidos anteriormente. }\end{array}$ \\
\hline
\end{tabular}

Fonte: Adaptado de Bukowitz e Williams (2002).

Nesse contexto, percebe-se a importância da gestão do conhecimento para o desenvolvimento das organizações, dessa forma, entende-se que se atrelarmos a interdisciplinaridade dentro das organizações, serão gerados melhores resultados, por meio da união dos conhecimentos específicos de cada área. Sendo assim, sugerese que a área de qualidade pode trazer grandes contribuições se atrelada à gestão do conhecimento com o auxílio das dimensões já descritas acima.

\subsection{GESTÃO DA QUALIDADE}

Gestão da qualidade pode ser vista, tanto no meio acadêmico como no âmbito empresarial, como uma ferramenta estratégica para a melhoria da competitividade e produtividade. Qualidade está associada à diversas óticas, como a durabilidade ou o desempenho técnico do bem referido, o grau em que o produto atende as satisfações e as necessidades do consumidor durante o uso, ou ainda, a partir de um terceiro entendimento sobre qualidade (que no passado era mais predominante no contexto fabril) sendo avaliada pela congruência do produto com as especificações do projeto (HEDEUS, 2000).

Muitas vezes, a qualidade é associada ao valor que corresponde o produto. 0 produto de qualidade é aquele que tem o desempenho esperado a um preço justo, sendo apresentado pela empresa a um nível apropriado e custo aceitável (MARTINS; LAUGENI, 2005).

Esse conjunto de sabedorias, analisada por Gavin (1992), mostra em parte a evolução do conceito de qualidade ao longo do século XX. No início dos anos de 1950, a qualidade do produto era entendida como sinônimo de perfeição técnica, ou seja, a qualidade era focada tanto no produto como na produção. Na década de 1950, com a divulgação do trabalho de Juran, qualidade passou a ser entendida como satisfação do cliente quanto à harmonização do bem ao uso. Satisfação está ligada a inexistência de defeitos e falhas e aparecimento de atributos que mantenham o produto adequado para o uso pretendido para causar satisfação (HEDEUS, 2000).

0 processo de melhoria contínua de produtos e processos envolve basicamente as seguintes etapas: identificação dos problemas prioritários; observação e coleta de dados; análise e busca de causas-raízes; planejamento e implementação das ações e verificação dos resultados (CARPINETTI,2012).

Nesse contexto, dentre as ferramentas da qualidade, pode-se encontrar: estratificação; folha de verificação; gráfico de Pareto; diagrama de causa e efeito; histograma; diagrama de dispersão e gráfico de controle. Outras ferramentas conhecidas como "As sete ferramentas gerenciais", são: diagrama de relações; diagrama de afinidades; diagrama em árvore; matriz de priorização; matriz de relações; diagrama de processo decisório (Process Decision Program Chart) e diagrama de atividades (diagrama de flechas). Além dessas ferramentas, outras são 
bastante difundidas: 5S; mapeamento de processos e 5W2H (what - o que será feito (etapas), why - por que será feito (justificativa), where - onde será feito (local), when - quando será feito (tempo), who - por quem será feito (responsabilidade), how - como será feito (método), how much - quanto custará fazer (custo)). Essas ferramentas podem ser utilizadas com as finalidades de identificar e priorizar os problemas; elaborar e implementar soluções e verificar os resultados, sendo feitas por meio de brainstorming (TRIVELLATO, 2010).

A partir dessas ferramentas, o sistema de gestão da qualidade ISO 9001 tem como objetivo evitar ou minimizar as ocorrências de não conformidades dos requisitos dos clientes, buscando um atendimento de excelência para a redução de desperdícios. A ISO propõe um misto de atividades de gestão, que devem contribuir para a minimização de não conformidades e desperdícios (NOGUEIRA, 2014).

O Desdobramento da função de qualidade QFD, do inglês Quality Function Deployment, é o modo usado no processo de desenvolvimento de produto que tem como o principal objetivo transformar requisitos de produto definidos pelo mercado em características do produto.Análise do modo e do efeito da falha (FMEA), do inglês Failure Made and Effect Analysis, é um método usado no desenvolvimento de produto e processo para desenvolvimento de ações de melhoria para sanar as falhas mais críticas. Pode ser usado na melhoria de produto ou no processo de fabricação, como também para desenvolver ações que visem reparar a chance de ocorrência de uma falha potencial (OLIVEIRA, 2014).

\section{MÉTODO}

No que tange aos procedimentos metodológicos, a presente pesquisa caracterizou-se como uma pesquisa descritiva, que de acordo com Gil (2010), é a que tem por objetivo a descrição de determinada população ou o estabelecimento da relação entre determinadas variáveis, neste caso, buscou-se compreender a influência da gestão do conhecimento e gestão da qualidade em uma empresa do ramo alimentício de Santa Maria. Também classificou-se como pesquisa exploratória, uma vez que pesquisas exploratórias têm por finalidade apresentar maior familiaridade com o problema de pesquisa, a partir de visitas ao local de estudo, apropriando-se de ideias ou intuições sobre o contexto em si (GIL, 2010).

Quanto aos procedimentos técnicos, a pesquisa desenvolveu-se por meio do método de estudo de caso na empresa do ramo Alimentício de Santa Maria/RS. Segundo Yin (2001, p. 32), um estudo de caso "é uma investigação empírica que investiga um fenômeno contemporâneo dentro de seu contexto da vida real, especialmente quando os limites entre o fenômeno e o contexto não estão claramente definidos", sendo que, o presente estudo buscou identificar as influências que a gestão do conhecimento e gestão da qualidade apresentavam na gestão da organização já identificada, sendo assim, compreender os fenômenos organizacionais a partir da literatura. Ainda, utilizou-se a pesquisa bibliográfica que para Marconi e Lakatos (2017, p. 63) tem o objetivo de "colocar o pesquisador em contato direto com tudo o que foi escrito, dito ou filmado sobre determinado assunto", o que foi realizado acessando artigos científicos, trabalhos acadêmicos, sites na internet, entre outras fontes. Também, ocorreram coletas de dados de documentos internos da empresa pesquisada, caracterizando-se, assim, como 
pesquisa documental, onde "a fonte de coleta de dados está restrita a documentos, escrita ou não, constituindo o que se denomina de fontes primárias" (MARCONI, LAKATOS, 2017, p. 53).

Quanto à coleta de dados, foram aplicadas diferentes técnicas. Primeiramente, foi aplicada uma entrevista semiestruturada junto à gestora da empresa, a fim de coletar informações sobre a administração do negócio desde seu planejamento e sobre a gestão da qualidade, visto que, as informações necessárias para o desenvolvimento do estudo . Na sequência, foi aplicado um questionário com a proprietária da organização, de forma presencial, formado por quatro seções de análise contendo 20 questões fechadas cada, totalizando 80 questões, a partir das quatro dimensões descritas na bibliografia (Obtenha, Utilize, Aprenda, Contribua) sendo adaptada das dimensões desenvolvidas por Bukowitz e Williams (2002). Ainda, foram realizadas visitas para estudo do ambiente, utilizando a técnica de observação não estruturada, que segundo Vergara (p. 76), “é aquela que não tem planejamento e controle e na qual o observador registra o acontecimento, porém, não utiliza recursos previamente definidos".

A análise dos dados se deu de forma qualitativa e quantitativa. Silva e Menezes (2001) definem que a pesquisa quantitativa considera que tudo pode ser quantificado, traduzida em números e informações para que assim possam ser classificadas e analisadas, e a pesquisa de cunho qualitativo descreve que o ambiente natural é a fonte direta para coleta dos dados, sendo assim assume uma posição descritiva.

As transcrições das entrevistas foram analisadas de forma qualitativa por meio da análise de conteúdo.. Para a análise dos questionários, foi realizada análise quantitativa, haja vista que a escala de mensuração do instrumento de coleta de dados foi composta de três pontos: "F - Representa que a afirmação é fortemente descritiva na minha organização"; "M - Representa que a afirmação é moderadamente descritiva na minha organização"; "Fr - Representa que a afirmação é fracamente descritiva na minha organização". Para a coleta e análise dos dados, foi utilizado o software MS Excel.

\section{RESULTADOS}

\subsection{IDENTIFICAÇ̃̃O DA EMPRESA}

A Cheirinho de Doce é uma empresa do ramo alimentício localizada na cidade de Santa Maria/RS, e iniciou suas atividades no mês de novembro do ano de 2017. A abertura do negócio foi motivada pelo feedback e incentivo de seus amigos e clientes, tendo em vista que já comercializavam seus produtos em sua própria residência por meio de encomendas e feiras no próprio condomínio onde residem.

A empresa tem como missão ser reconhecida pelos produtos artesanais de qualidade que oferecem ao seu cliente, tendo em vista que uma das necessidades do seu público é o consumo de produtos naturais e sem conservantes e/ou misturas prontas. Nesse ínterim, conta com um cardápio diversificado de produtos quentes e frios, doces e salgados feitos artesanalmente pela própria empresa.

De acordo com os resultados obtidos com a entrevista semiestruturada, é possível destacar que a empresa antes de sua abertura realizou um plano de 
negócios traçando as metas e objetivos para os próximos 5 anos de atividade da empresa, contando também com o apoio da incubadora da Universidade Franciscana, que realizou pesquisas de mercado para empresa, buscando compreender os desejos, necessidades e a opinião dos mesmos sobre possíveis posições que a empresa adotaria, como é o caso de um espaço para animais na empresa que não foi aceito pela comunidade.

No âmbito sustentável e social a empresa realiza a doação de alimentos e produtos em condições de consumo que não serão comercializados pela mesma devido à demanda e escala de funcionamento, a organização realiza também a arrecadação de doações para instituições que cuidam de animais no bairro de Camobi da cidade. As estratégias de público alvo,são mais voltadas ao público feminino, pelo maior consumo de produtos e ambientes como da confeitaria, mas não restringe e nem, descarta o consumo por outros públicos, nesse caso o sexo masculino.

\subsection{QUANTO À GESTÃO DA QUALIDADE}

Frente ao mercado, a empresa busca ser reconhecida pelos seus produtos completamente artesanais, com qualidade diferenciada, feitos pela própria empresa. Mas, dentro do seu ambiente interno a empresa acredita que precisa melhorar e capacitar seus colaboradores para que consiga também atingir a qualidade e excelência no seu atendimento, nesse sentido a empresa acredita na formação de novos potenciais contratando colaboradores sem experiência na área e capacitando os mesmos com cursos e treinamentos.

0 diagnóstico inicial para iniciar as atividades da empresa, foram a partir da venda dos seus produtos e o feedback positivo recebido pelos clientes, tornandose um indicador de qualidade e reconhecimento da empresa e dos seus produtos. Um dos principais objetivos da organização é tornar-se uma franquia do ramo alimentício, para isso acredita que é importante estar dentro das normas de qualidade, indicadores e certificações, mas como para obtenção dos mesmos, demanda de um custo alto, não tem disponibilidade para a implementação das mesmas no momento.

\subsection{QUANTO A GESTÃO DO CONHECIMENTO}

Sobre as quatro dimensões pesquisadas, a respeito da gestão do conhecimento, pode-se verificar que, na seção 1, denominada Obtenha, a empresa alcançou uma pontuação final de 57 pontos representando 95\% de aproveitamento, que se justifica pela disseminação do conhecimento de forma clara e completa a todos os níveis da organização.

Na seção 2, denominada Utilize, a empresa atingiu uma pontuação total de 54 pontos, representando um percentual de aproveitamento de $90 \%$ nas questões que abordam o tema. Nesta seção, percebeu-se um crescimento de respostas moderadas explicadas pela caracterização rígida da empresa em que alguns processos poderiam ser mais flexibilizados, tais como reuniões não estruturadas para facilitar o processo criativo. 
Na seção 3, identificada como aprenda, a empresa a partir das respostas atingiu 54 pontos, representando assim 90\% de aproveitamento. É possível destacar como curiosidade e ponto a ser melhorado, que a empresa precisa saber identificar possíveis falhas e tirar novos aprendizados a partir dos mesmos.

Na seção 4, denominada Contribua, a empresa fez 51 pontos representando 85\% de aproveitamento. Destaca-se o aparecimento de duas questões de forma Fraca dentro da empresa, sendo elas:- As pessoas que se recusam a compartilhar conhecimento não obtém certos benefícios organizacionais;- Nós ligamos as pessoas por meio de unidades organizacionais e grupos funcionais tradicionais para promover o compartilhamento do conhecimento.

Assim, na Tabela 1 são demonstrados os resultados quantitativos de forma agrupada:

Tabela 1 - Análise dos resultados quantitativos

\begin{tabular}{|c|c|c|}
\hline DIMENSÃO & PONTUAÇÃO & APROVEITAMENTO \\
\hline Obtenha & 57 & $95 \%$ \\
\hline Utilize & 54 & $90 \%$ \\
\hline Aprenda & 54 & $90 \%$ \\
\hline Contribua & 51 & $85 \%$ \\
\hline
\end{tabular}

Fonte: Dados da pesquisa (2018).

Diante exposto, percebe-se que de forma geral a empresa atende a todos os requisitos do método de forma positiva, apesar de ser um negócio recente na cidade de Santa Maria. Ainda, destaca-se que a gestora executou seu projeto Cheirinho de Doce com planejamento.

Os resultados da pesquisa apontaram lacunas a serem preenchidas na gestão da empresa, como no caso das ferramentas da qualidade, por outro lado, existem ferramentas que não geram grandes custos que resolvem problemas até mesmo no âmbito da gestão do conhecimento que se encontra como alguns pontos fracos da empresa. Sugere-se então uma ferramenta que pode ser desenvolvida que é o ciclo PDCA que promove melhorias contínuas para organização (BERTOLINO, 2011).

\section{CONCLUSÃO}

Concernente a abordagem do estudo, percebe-se grande influência dos dois fatores estudados para o meio organizacional. A gestão do conhecimento auxilia o administrador a identificar a importância da disseminação do conhecimento para organização (ALMEIDA, 2011). De acordo com Carpinetti (2016), a gestão da qualidade traz o conceito de inovação contínua tanto de processos e produtos como de buscando constantemente adequação às especificações, uso, custo e requisitos necessários para determinada área efetiva. Para tanto o trabalho foi aplicado na empresa Cheirinho de Doce, empresa do ramo alimentício localizada na cidade de Santa Maria/ RS, para ratificar de forma concreta como as abordagens atuam na organização e se a empresa atendia aos requisitos demandados do trabalho. 
Referente aos objetivos específicos, ao verificar quais ferramentas da qualidade, indicadores de qualidade e, certificações relacionadas a qualidade e produtividade, existentes e/ou necessárias, percebeu-se que a empresa iniciou usando como indicador, a satisfação dos clientes, destacando que deseja atender as especificações e certificações necessárias para qualificação ainda maiores. Para avaliar as dimensões da estruturação da gestão do conhecimento, empresa atendeu aos quesitos apresentados, podendo se considerar uma média positiva com relação às dimensões da gestão do conhecimento e entendeu-se que existem pontos a serem melhorados na disseminação do conhecimento dentro da mesma.

Sendo assim, compreendeu-se que na organização, os dois fatores estão de alguma forma estruturados, e as questões que ainda não foram atendidas já estão pautadas para serem executadas em longo prazo. Ademais, sugere-se a implementação de ferramentas para gestão da qualidade como o PDCA e o 5W2H, as quais têm baixo custo de implementação e proporcionam aproximação ainda maior dos colaboradores para crescimento pessoal e interpessoal. Também, podemse desenvolver facilitadores de compartilhamento de conhecimento que agregam valor ainda maior para identidade da empresa.

Ao verificarem-se as limitações que foram encontradas durante a realização do presente estudo, observou-se a dificuldade de encontrar momentos em que os proprietários pudessem dedicar-se somente a passar as informações que constituem a organização. Haja vista que, a empresa ainda tem um porte pequeno, então conta com equipe de colaboradores pequena, nesse sentido, os proprietários por muitas vezes, fazem parte da grade de colaboradores disponíveis ao atendimento dos clientes.

Sugere-se assim, que sejam realizados novos estudos envolvendo as temáticas da gestão do conhecimento e principalmente a gestão da qualidade nas organizações da cidade de Santa Maria. Justificando-se pelo alto índice de estabelecimentos encontrados na cidade, e que há uma grande parte da população que se destina ao campo científico, entendendo assim, que a junção dessas áreas pudessem fornecer um melhor desempenho das organizações definindo melhor sua atuação no mercado, influenciando assim, na economia local em tempos de crise econômica e suba da inflação.

\section{REFERÊNCIAS}

BERTOLINO, Marco Túlio. Gerenciamento da Qualidade na Indústria Alimentícia. Porto Alegre: ArtMed, 2011. [e-book]

BRASIL. Plano de Negócios. Brasília: Governo Federal, 2011. Disponível em: <http://www.brasil.gov.br/economia-e-emprego/2011/11/plano-de-negocios>. Acesso em: 14 abr. 2018.

BUKOWITZ, W. R.; WILLIAMS, R. L. Manual de gestão do conhecimento. Tradução: Carlos Alberto Silveira Netto Soares. Porto Alegre: Bookman, 2002.

CARPINETTI, Luiz Cesar Ribeiro. Gestão da Qualidade: Conceitos e Técnicas. 2 ed. São Paulo: Editora Atlas S.A, 2012.

DELLA MEA, Diana; NAGEL, Mateus; SANTOS, Leandro Dorneles dos. Projeto de Pesquisa Interdisciplinar (PPI): A relação entre Plano de Negócios, Gestão do Conhecimento e Gestão da Qualidade. Santa Maria: FISMA, 2018.

DRUCKER, Peter Ferdinand. Aprendizagem organizacional. São Paulo: Campus, 1990. 
GIL, Antonio Carlos. Como Elaborar Projetos de Pesquisa. 5ae ed. São Paulo: Atlas, 2010.

HEDEDUS, Clovis Eduardo Nunes. A compreensão da percepção da qualidade pelo consumidor como base para a definição de estratégias pelas empresas e suas cadeias de fornecimento. Dissertação (Mestrado). Escola Politécnica da Universidade de São Paulo. São Paulo, 2000.

MARCONI, Marina Andrade, LAKATOS, Eva Maria. Técnicas de Pesquisa, 8. ed. São Paulo: Atlas, 2017. [e-book].

NAKAGAWA, Marcelo. Plano de negócio: teoria geral. Barueri/SP: Manole, 2011.

NOGUEIRA, Vanessa Otoni. Processo de Implementação da Norma IS09001:2008 Em uma Indústria Eletrônica. Trabalho de Conclusão de Curso. Universidade Federal de Juiz de Fora. Juiz de Fora, 2014.

OLIVEIRA, Otávio J. Curso básico de Gestão da Qualidade. São Paulo: Cengage Learning Editores, 2014. [e-book].

RIBEIRO, Luiz Cesar. Gestão da Qualidade: conceitos e técnicas. 3. ed. - São Paulo: Atlas, 2016.

SEBRAE. Como elaborar um plano de negócios. Sebrae Nacional, 2018. Disponível em: $<$ http://www.sebrae.com.br/sites/PortalSebrae/bis/documento-ensina-a-montar-plano-denegocio,7f0c26ad18353410VgnVCM1000003b74010aRCRD>. Acesso em: 15 abr. 2018.

SEBRAE. Fundamentos da Gestão da Qualidade. Sebrae Nacional, 2016. Disponível em: <http://www.sebrae.com.br/sites/PortalSebrae/artigos/fundamentos-da-gestao-daqualidade,527e438af1c92410VgnVCM100000b272010aRCRD>. Acesso em: 14 abr. 2018.

SHINYASHIKI, Gilberto Tadeu; TREVIZAN, Maria Auxiliadora; MENDES, Isabel Amélia Costa. Sobre a criação e a gestão do conhecimento organizacional. Revista Latino-americana de Enfermagem, USP. 2003, vol.11, n.4, pp.499-506. Disponível em: http://www.scielo.br/scielo.php?pid=S0104$11692003000400013 \&$ script=sci_abstract\&tlng=pt. Acesso em 14 abr. 2018

SILVA, Edna L. da; MENEZES, Estera M. Metodologia da pesquisa e elaboração de dissertação. 3. ed. rev. atual. Florianópolis: Laboratório de Ensino a Distância da UFSC, 2001.

TRIVELLATO, Arthur Antunes. A aplicação das sete ferramentas básicas da qualidade no ciclo PDCA para a melhoria continua: estudo de caso numa empresa de autopeças. Trabalho de Conclusão de Curso - Escola de Engenharia de São Carlos, Universidade de São Paulo. São Carlos, 2010, p. 72.

VERGARA, Sylvia Constant. Métodos de coleta de dados no campo. 2. ed. São Paulo: Atlas, 2012. [ebook].

YIN, Robert K. Estudo de caso: planejamentos e métodos. 2. ed. Porto Alegre: Bookman, 2001. 